\title{
Discussion of Foster \& Brown's Time and Tide: Analysis of Sea Level Time Series
}

\author{
A. Parker ${ }^{1^{*}}$ and C. D. Ollier ${ }^{2}$ \\ ${ }^{1}$ School of Engineering and Physical Science, James Cook University, Townsville QLD 4811, \\ Australia. \\ ${ }^{2}$ School of Earth and Environment, The University of Western Australia, Crawley 6009 WA, Australia.
}

Authors' contributions

This work was carried out in collaboration between both authors. The authors equally contributed to the paper. Both authors read and approved the final manuscript.

Article Information

DOI: $10.9734 / P S I J / 2015 / 15652$

Editor(s):

(1) Stefano Moretti, School of Physics \& Astronomy, University of Southampton, UK.

Reviewers:

(1) Anonymous, China.

(2) Maher A. El-Hallaq, Surveying and Geodesy, Civil Engineering Department, The Islamic University of Gaza, Gaza, Palestine.

(3) Wen-Cheng Liu, Department of Civil and Disaster Prevention Engineering, National United University, Taiwan.

(4) Anonymous, Brazil.

(5) Anonymous, China.

Complete Peer review History: http://www.sciencedomain.org/review-history.php?iid=837\&id=33\&aid=8091

\section{Commentary}

Received $9^{\text {th }}$ December 2014

Accepted $30^{\text {th }}$ January 2015

Published $10^{\text {th }}$ February 2015

\begin{abstract}
The recognition of the non-accelerating, periodic pattern of sea levels as described by the tide gauges measurements does not require any special mathematical tool. Providing enough data of sufficient quality have been recorded, If the classical linear fitting is used to compute the rate of rise at any time, then the acceleration is simply the time rate of change of this velocity. By using this technique, the lack of any acceleration over the last few decades is evident in the naturally oscillating, slow rising, tide gauges of appropriate quality and length. Contrary to what is claimed in the commented paper, the accuracy in the computation of the periodicities of the natural oscillations does not impact at all on this result. As the measured sea level oscillations are not perfectly sinusoidal, clearly different assumptions about the shape of the periodic functions, their number and the definition of the algorithm used to compute the parameters of the selected periodic functions all affect the determination of the periodicities. This has however very little influence on the present sea level debate questioning the presence or the absence of acceleration at the tide gauges.
\end{abstract}

*Corresponding author: Email: albert.parker.2014@gmail.com, albertparker@y7mail.com; 
Keywords: Sea level rise; sea level acceleration; sea level oscillations; computations; experiments.

\section{INTRODUCTION}

Analyses of the sea levels recorded by the tide gauges have shown that contrary to the IPCC claim, there has been no sign of carbon dioxide driven acceleration since the 1950. The sea levels are mostly oscillating, on average slow rising with a rate close to the subsidence rate of the tide gauge, and absolutely not accelerating over the last few decades $[1,2,3]$.

According to [4], the papers that have examined sea level data to estimate the pattern of acceleration and deceleration proposing cyclic or quasi-periodic variations "contain technical problems which call their results into question". In this way, the authors try to make unclear what is otherwise very evident, defocusing the debate from the striding differences from the pattern predicted by the Intergovernmental Panel on Climate Change (IPCC) climate models and the actual measurements at the tide gauges.

The existence of natural, multi-decadal oscillations up to a quasi-60 years is a very wellknown feature of sea levels. As evidenced by [1], all the climate-related phenomena, including the sea-level, change through time in a nonstationary way and exhibit repetitive (though not exactly regular) patterns of behavior decadal and multi-decadal periods. Changes in the rate of global sea-level are, for example, known to be influenced by a 50-60 year rhythm related to oceanic internal variability e.g., Pacific Decadal Oscillation, PDO; Atlantic Meridional Oscillation, AMO (e.g. $[5,6,7,8,9])$. Long period tidal constituents (the 18.6 lunar nodal cycle, for example) also exert an influence on sea-level height (e.g. [10,11]). [12] discussed the influence of the Helios sphere and the Earth magnetosphere on the climate on Earth. The solar-planetary beat has a 60 -years cycle. The Earth's rate of rotation has a 60-years Length of Day (the standard method to measure the Earth's rate of rotation) cycle. The Global temperature has a 60 years cycle. The North Atlantic circulation has a 60 years cycle. The 60years cycle recorded in solar activity and earth rotation affects the oceanic circulation, the temperatures and the sea levels.

While the existence of multi-decadal oscillations is very difficult to be negated, the autocorrelation issue raised by [4] did not put in question the existence of the natural fluctuations but at the most the accuracy of the computation of the amplitudes, phases and periodicities of the oscillations. As a matter of fact, the most part of the work on the multi-decadal periodicities claim the existence of quasi-20 or quasi-60 year's periodicities, and not certainly of perfectly sinusoidal oscillations of time periods computed within an accuracy of the nanoseconds. It is shown with a simple methodology as the sea levels are not accelerating and the issues raised by Foster \& Brown (2014) are irrelevant.

\section{METHODOLOGY}

Many tide gauges are recording the relative sea levels since the 1800s and the early 1900s in coastal locations worldwide and the linear analysis of the monthly average values has been historically the method of determining the relative rate of rise [8]. Because of the quasi-60 years oscillations, [1] concluded that sea-level records longer than 60 years, and even better longer than 120 years, are required to identify any longterm trends that might, or might not, occur in the data. Considering not too many tide gauges are measuring sea levels since more than 120 years ago without any quality issues, $[8,2]$ suggested using tide gauge signals continuously covering more than 60 years without many gaps and without any perturbing event as the relocation or substitution of the tide gauge.

The assessment of the presence (or absence) in the tide gauge records of enough length and quality of any acceleration induced by the anthropogenic carbon dioxide emission claimed by the climate model is then very simple. The simple mathematics has been proposed in $[8,2]$ and other papers and it is reproduced below.

The relative rate of rise SLR is computed through the linear fitting applied to the distribution of measured points $\left\{x_{i}, y_{i}\right\} i=1, \ldots, n$ where $y_{i}$ is the monthly average relative mean sea level at the time $x_{i}$. The relative rate $S L R_{j, k}$ is computed over the time window $\left(\mathrm{x}_{\mathrm{k}}-\mathrm{x}_{\mathrm{j}}\right)$ by linearly fitting the data $\left\{x_{i}, y_{i}\right\} i=j, \ldots, k$ through the formula:

$$
S L R_{j, k}=\frac{\sum_{i=j}^{k}\left(x_{i}-\bar{x}\right) \cdot\left(y_{i}-\bar{y}\right)}{\sum_{i=j}^{k}\left(x_{i}-\bar{x}\right)^{2}}
$$

Where $\bar{x}$ and $\bar{y}$ are the sample means. 
If $\mathrm{j}=1$ (the oldest record) and $\mathrm{k}=\mathrm{n}$ (the latest record), then $\mathrm{SLR}_{1, \mathrm{n}}$ is the latest estimation of the relative rate of rise at the time $x_{n}$.

If $\mathrm{j}$ is variable and $\mathrm{k}=\mathrm{n}$, then $S L R_{\mathrm{i}, \mathrm{n}}$ is the present velocity for different time windows $x_{n}-x_{i}$, simulating the effect of the tide gauge recording started at different times $\mathrm{x}_{\mathrm{i}}$ rather than $\mathrm{x}_{1}$ (Parker et al. [8]; Parker, [2]).

If $\mathrm{j}=1$ (the oldest record) and $\mathrm{k}$ is variable, then $\mathrm{SLR}_{1, \mathrm{k}}$ is the estimation of the relative rate of rise at the time $x_{k}$.

From Equation (1) with $\mathrm{j}=1$ and $\mathrm{k}$ variable it is possible to compute the acceleration:

$$
S L A_{k}=\frac{S L R_{1, k}-S L R_{1, k-1}}{x_{k}-x_{k-1}}
$$

To help understanding the effect of the multidecadal oscillation, the measured data may be replaced with a fitting with a line and multiple sines $[8,2]$. This fitting with a line and sines has the expression:

$$
y^{*}(x)=\left(A^{*}+S L R^{*} \cdot x\right)+\sum_{i=1}^{n}\left[A_{i} \cdot \sin \left(\pi \cdot \frac{x-x_{c, i}}{w_{i}}\right)\right]
$$

Where $y^{*}$ is the fitted relative sea level and the time $x, S^{*} R^{*}$ is the relative rate of rise and $A^{*}$ is the intercept, while $A_{i}, x_{c, i}, w_{i}$ are the amplitudes, phases and periods of the oscillations permits to study the effect of the natural oscillations. It is worth to mention that equation (3) may also provide a tool to fill the gaps eventually available in a time series.

\section{RESULTS}

Application of equation (1) and equation (2) to a proper data set is enough to confute all the sea level accelerating claims without any need of hypothetically more sophisticated measurement and analysis tools only contributing to make more confused a worldwide sea level pattern that is otherwise very clear.

The surveys of relative sea level rates of rise global or local by many organizations as Permanent Service for Mean Sea Level (PSMSL, www.psmsl.org) or National Oceanic and Atmospheric Administration (NOAA, www.noaa.gov) may be used to evaluate the acceleration by using the relative sea level rates of rise computed for the same tide gauge at two different times.

As also reported elsewhere, the latest PSMSL "Table of Relative Mean Sea Level Secular Trends derived from PSMSL RLR Data" update 14-Feb-2014 [3] proposes the relative rates of rise computed for 560 tide gauges of variable record length (maximum 183, minimum 21, average 56.5 years) with the more recent, shortest tide gauges collected mostly in areas of subsidence and a strongly non-uniform geographical coverage.

The use in different times of different populations of tide gauges of different length, different rates of subsidence or uplift, and different parameters of the oscillations is what permits the false claim the sea level have been accelerating over the last decades by cherry picking when actually all the long term tide gauges of the world have been on average acceleration free.

The average relative rate of rise of the 560 tide gauges is $1.04 \pm 0.45 \mathrm{~mm} /$ year, but this number has very little significance. By only using the 170 tide gauges of PSMSL having length more than 60 years at the present time, the average relative rate of rise is $0.25 \pm 0.19 \mathrm{~mm} / \mathrm{year}$. If we want to study the changes in the rate of rise of sea levels over the satellite altimeter era, we do not have to consider the 100 tide gauges of PSMSL having length more than 80 years at the present time are 100 , i.e. more than 60 years of length 20 years ago, and the average rate of rise for them is $0.24 \pm 0.15 \mathrm{~mm} /$ year. For these tide gauges, the rate of rise has been moving up and down over the last 20 years without any sign of globally positive or negative accelerations.

In additions of being acceleration free, these tide gauges are on average more subjected to subsidence than uplift, as suggested by the nearby GPS dome velocities by the Système d'Observation du Niveau des Eaux Littorales (SONEL, www.sonel.org). Therefore the worldwide tide gauge signals suggest slow rising seas without any acceleration and with a significant component of subsidence.

The result of this synthetic analysis may be complemented by the analysis through equations (1) and (2) of the long term sea level time series. All the long term tide gauges exhibit pretty much the same pattern. Therefore, we select here the Sydney and San Diego tide gauges, on the west and east shores of the Pacific, in the southern and northern hemisphere. 
Figs. 1 and 2 present the mean sea level measured in Sydney and San Diego, plus the results obtained by replacing the measured data with a fitting with a line and multiple sines. Equations (1) and (2) are applied to both time series to show what natural oscillation is and what is noise. The figures also present the vertical position and the subsidence rate of inland GPS domes nearby the tide gauges. Application of equations (1) and (2) to the perfectly oscillating zero acceleration time series may return positive or negative accelerations depending on the time window.

In Fig. a) is the classic trend computation (from tidesandcurrents.noaa.gov/sitrends/). The standard error or the $95 \%$ confidence interval is only a measure of the linear fitting error. The "true" relative rate of rise is not the computed value \pm the standard error or the $95 \%$ confidence interval. With short and incomplete records the computed value may be very far from the legitimate value. Other measurement issues, including variable subsidence at the tide gauge or relocation of the tide gauge or inaccurate levelling, may also bias the result.

In Fig. b) is the measured monthly averaged mean sea levels and the fitted values from equation (3). The 36 months moving averaged are superimposed. The perfectly not accelerating model reproduces quite well the experimental evidence even if the experimental evidence is much more complex and the noise of the measurement is significant.

In Fig. c) is the same monthly averaged mean sea levels of Fig. b) but de-trended, i.e. the monthly values minus their linear trend values. In Fig. d) is the SLR computed from the measured and the fitted data over the last 20 years. Over the time window 1993 to present, the measured SLR of Sydney is slightly increasing since 1999, while the measured SLR of San Diego is slightly decreasing since same year. Before that time, the trend was inverted, as a result of oscillations that are not in phase. Same pattern is shown by the fully periodical fitting. This is the only result of interest to assess the effect of global warming, and clearly having a more or less accurate model (3) has no impact on the conclusion.

In Fig. e) is the present SLR computed from the measured and the fitted data by using different record length. Unfortunately, the long tide gauges records having more than 100 years of data are not too many, and in many cases SLR are computed by using short record lengths. With short record lengths the computed SLR differ considerably from the legitimate long term SLR. The measured 20 years SLR for Sydney is more than 5 times the correct value, while the measured 20 years SLR of San Diego is more than 10 times smaller.

Even if many papers have wrongly claimed the hot spot of positive but never the cold spot of negative acceleration, this conclusion is only the result of cherry picking the information between a valley and a peak of an oscillation rather than between a peak and a valley. The pattern proposed in Fig. $\mathbf{e}$ is only the result of the periodicities, amplitudes, phases of the oscillations and the time window. Same pattern is shown by the not accelerating fitting.

In Fig. f) is the subsidence trend of GPS domes nearby the tide gauges (from www.sonel.org). This unfortunately not very accurate result suggests a subsidence rate very close to the relative rate of rise of sea levels for both Sydney and San Diego for a close to zero absolute rate of rise in both locations. The vertical velocity of the Sydney SYDN GPS dome is $-0.89 \pm 0.65$ $\mathrm{mm} /$ year. Subsidence velocity of GPS domes nearby the San Diego tide gauge are $-1.65 \pm 0.41$ $\mathrm{mm} /$ year (Point Loma 3, PLO3) and -3.23 \pm 0.17 $\mathrm{mm} /$ year (Point Loma 5, PLO5).

Figs. 3 and 4 are the periodogram of the measured and fitted sea level patterns in Sydney and San Diego. Images a) and b) and data of c) are obtained by [13].

In Fig. a) is the periodogram spectrum vs. frequency (in months ${ }^{-1}$ ) of the measured monthly average mean sea levels while in Fig. b) is the periodogram spectrum vs. frequency (in months ${ }^{-1}$ ) of the monthly average mean sea levels from the fitting with a line and sines. The measured values have a very different signature, with the fitted values obviously evidencing the simulated periodicities.

In Fig. c) is the periodogram spectrum vs. period (in months) of the measured and fitted monthly averages. In case of San Diego, the record length is smaller, and the longer periodicity is consequently less well evidenced than in Sydney. To properly compute a periodicity, the record length must be many times the period length and this is unfortunately never the case. 

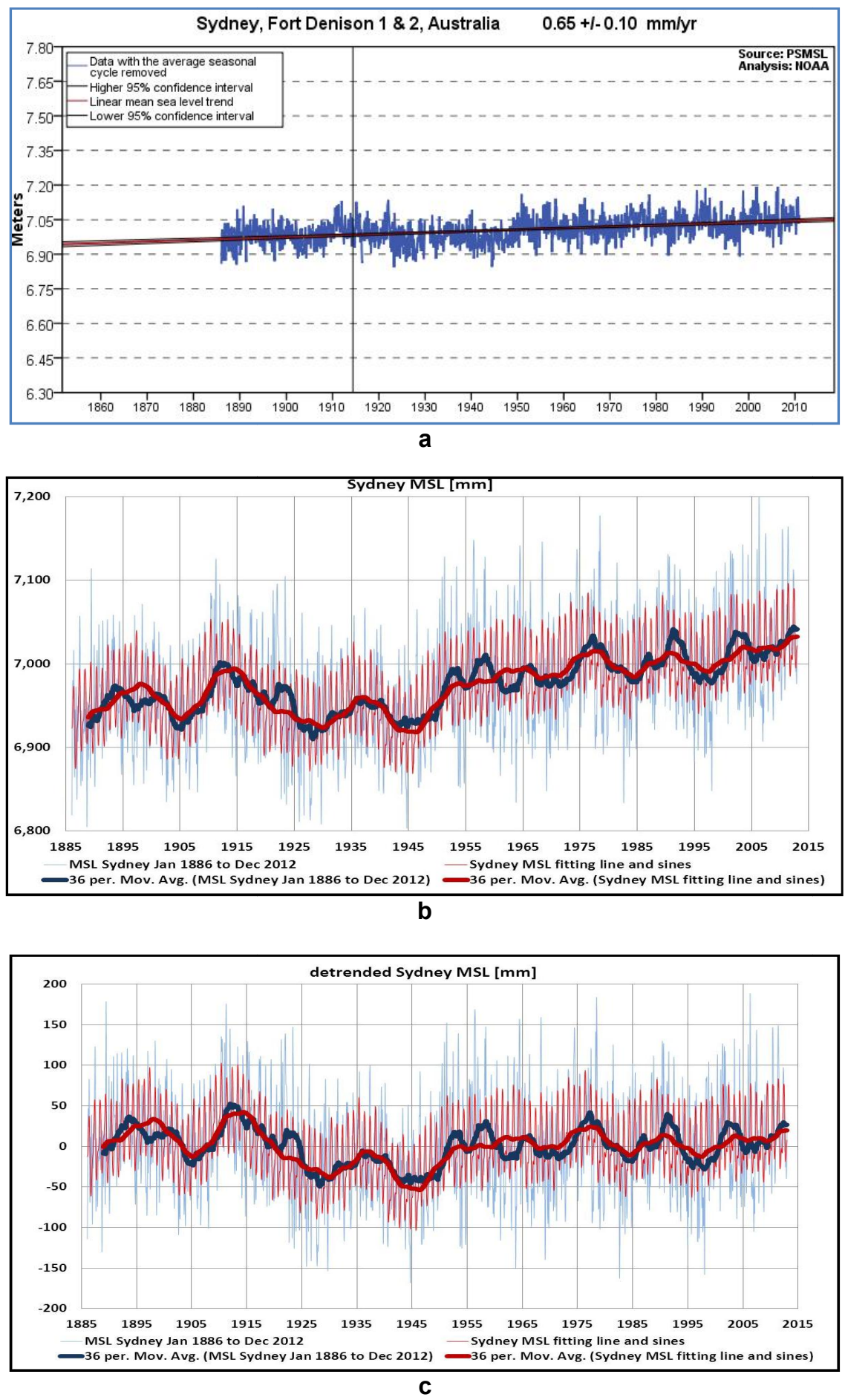

Fig. 1. Continues - measured and fitted sea level patterns in Sydney (a) classic trend computation (from tidesandcurrents.noaa.gov/s/trends/). Relative sea level velocity is $+0.65 \pm 0.10 \mathrm{~mm} /$ year; b) measured and fitted (equation (3)) monthly average mean sea levels; c) detrended monthly average mean sea levels; d) SLR over the last 20 years.e) present SLR by using different record lengths; f) GPS velocity nearby the tide gauge (from www.sonel.org). Subsidence velocity is $-0.89 \pm 0.65 \mathrm{~mm} / \mathrm{year}$. 

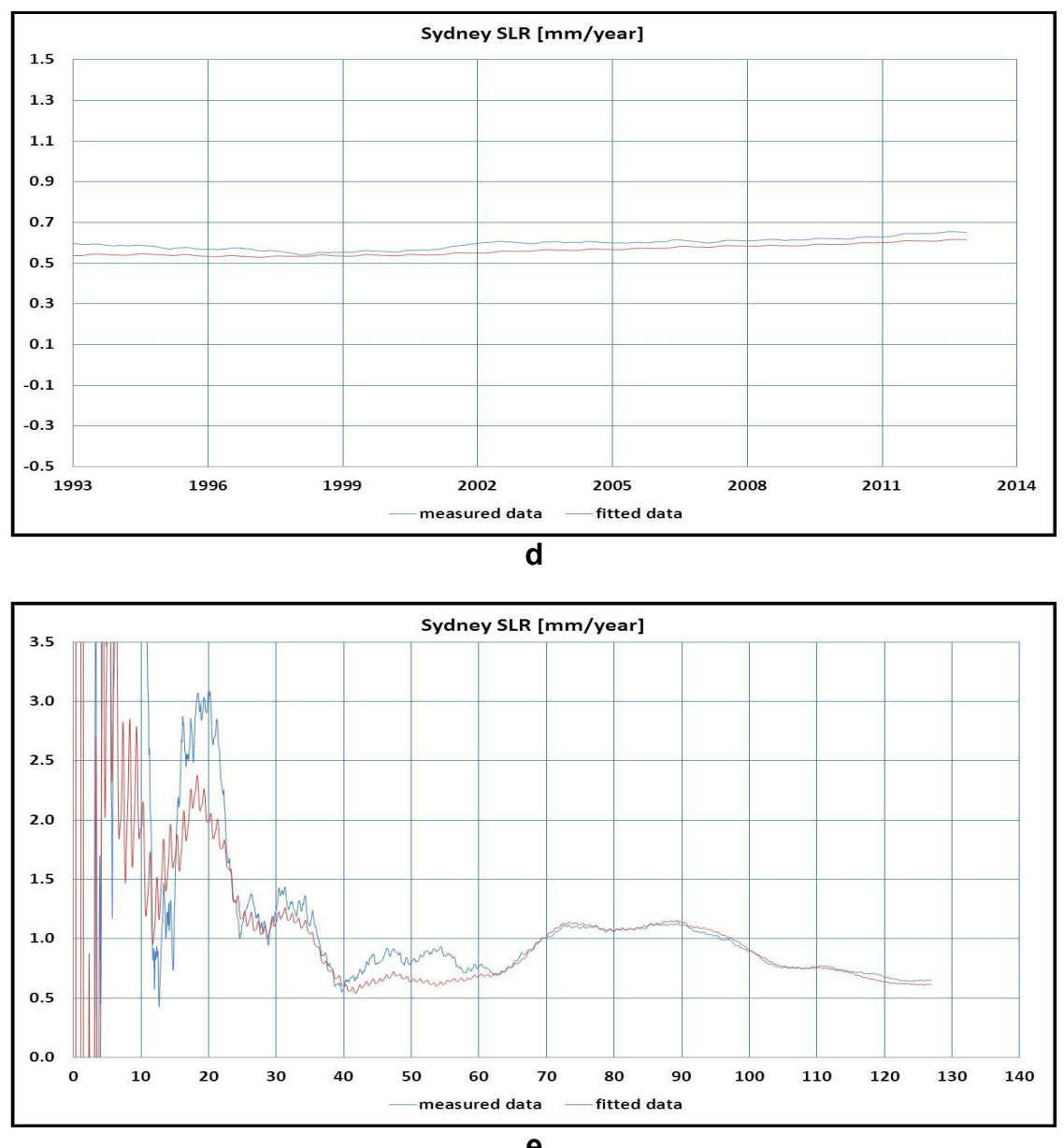

e

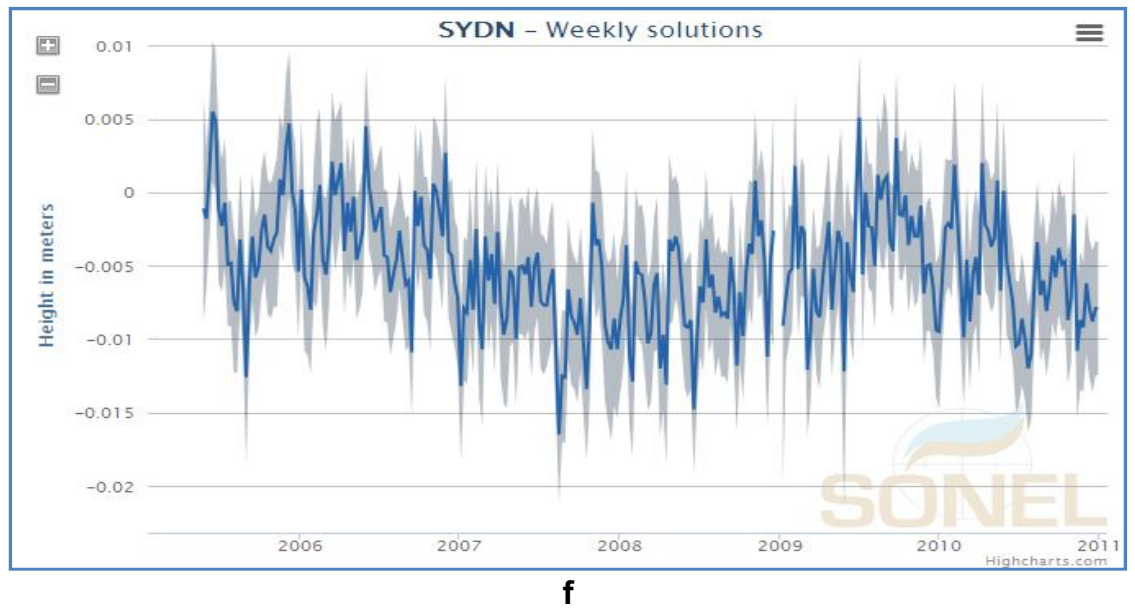

Fig. 1. Continued - measured and fitted sea level patterns in Sydney (a) classic trend computation (from tidesandcurrents.noaa.gov/s/trends/). Relative sea level velocity is $+0.65 \pm 0.10 \mathrm{~mm} /$ year; b) measured and fitted (equation (3)) monthly average mean sea levels; c) detrended monthly average mean sea levels; d) SLR over the last 20 years.e) present SLR by using different record lengths; f) GPS velocity nearby the tide gauge (from www.sonel.org). Subsidence velocity is $-0.89 \pm 0.65 \mathrm{~mm} / \mathrm{year}$. 

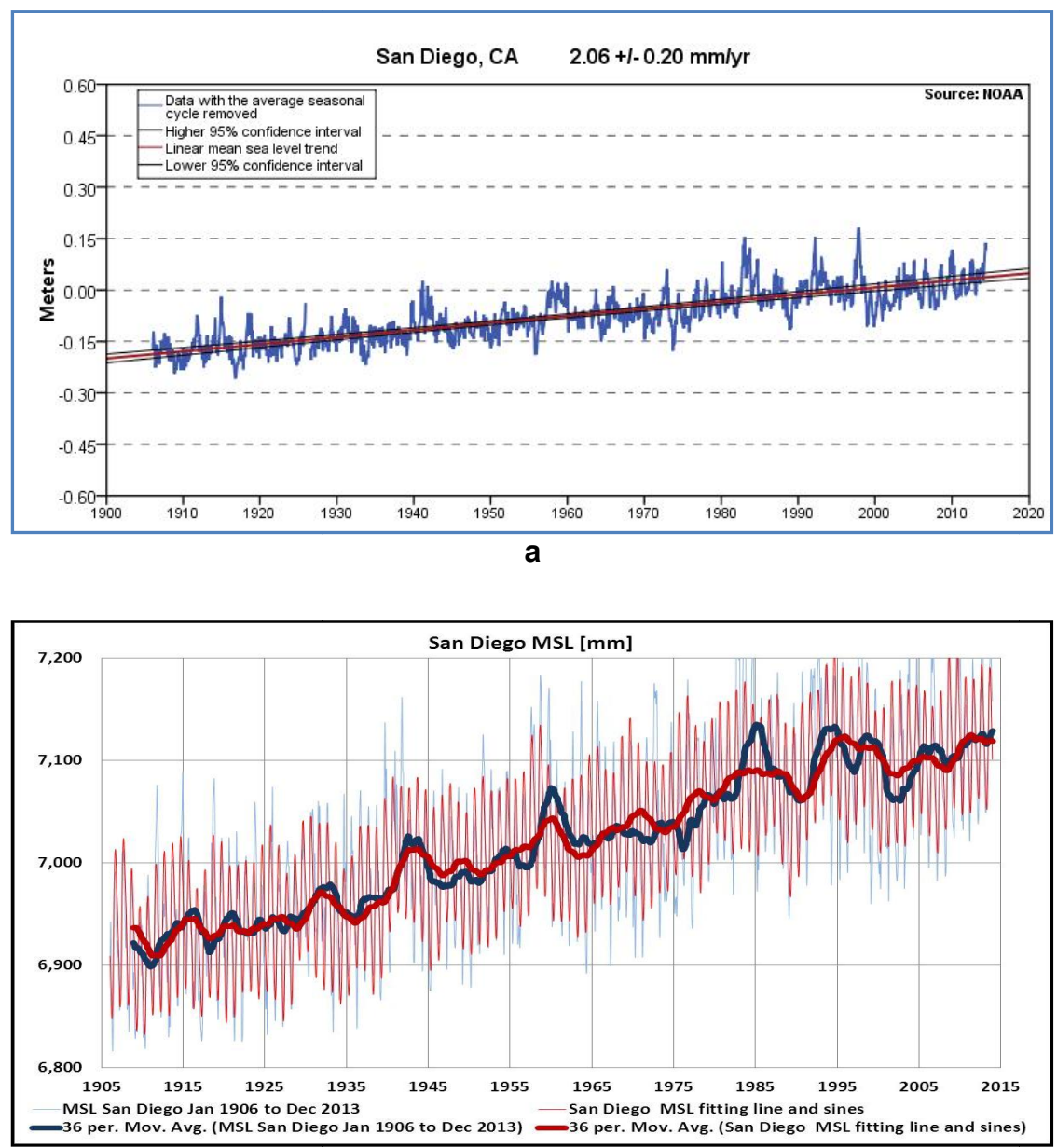

b

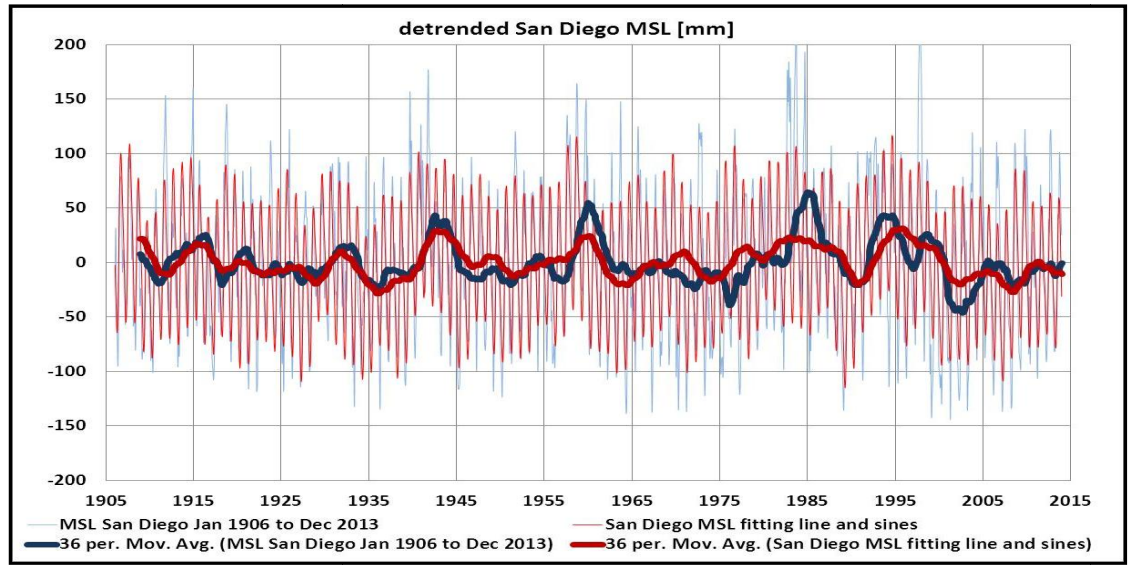

C

Fig. 2. Continues- measured and fitted sea level patterns in San Diego

a) classic trend computation (from tidesandcurrents.noaa.gov/s/trends/). Relative sea level velocity is $+2.06 \pm 0.23$ $\mathrm{mm} /$ year; b) measured and fitted (equation (3)) monthly average mean sea levels; c) detrended monthly average mean sea levels; d) SLR over the last 20 years.e) present SLR by using different record lengths; f) GPS velocity nearby the tide gauge (from www. sonel.org). Subsidence velocities of nearby domes are $-1.65 \pm 0.41 \mathrm{~mm} / \mathrm{year}$

(Point Loma 3, PLO3) and $-3.23 \pm 0.17 \mathrm{~mm} /$ year (Point Loma 5, PLO5) 

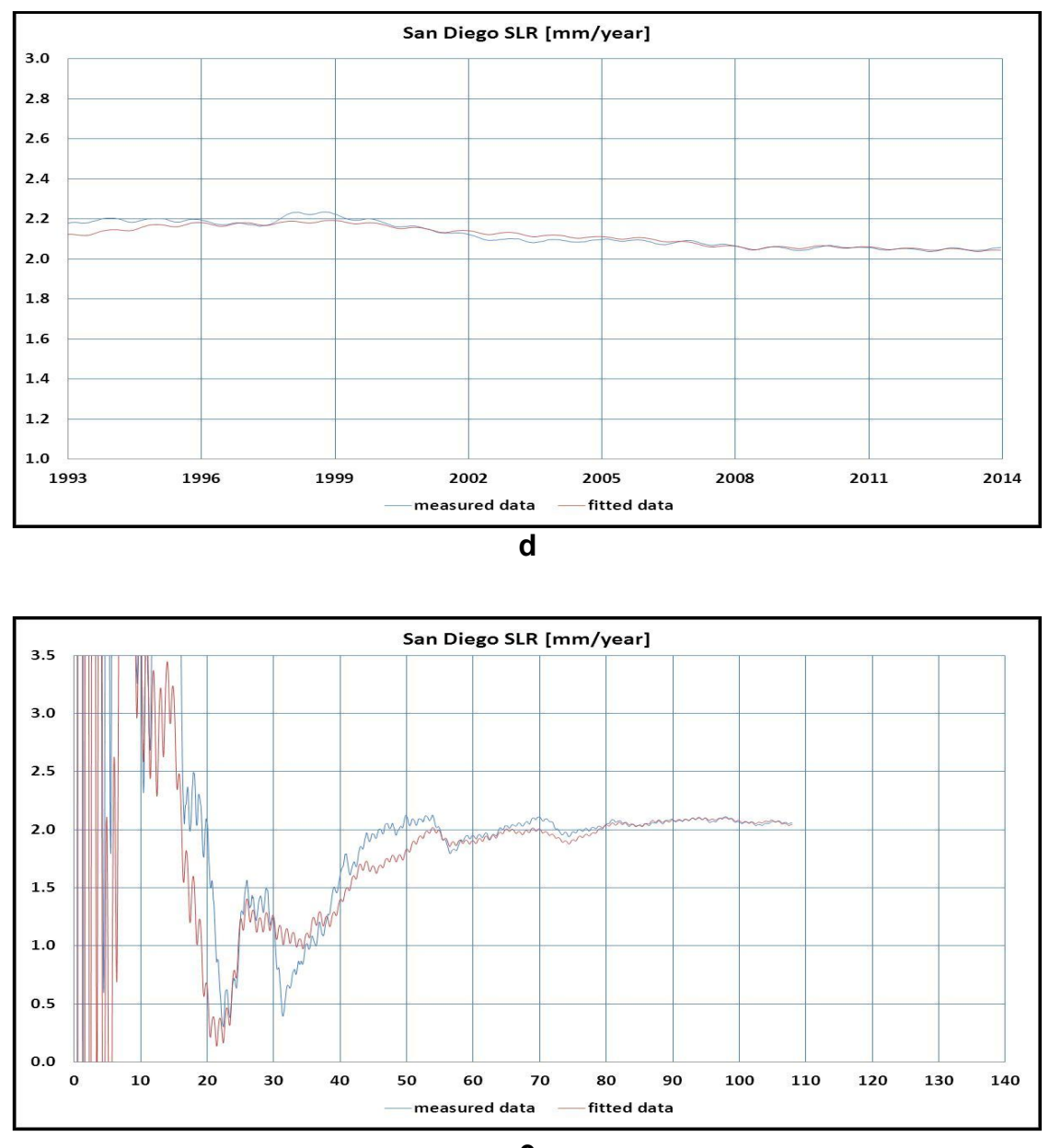

e

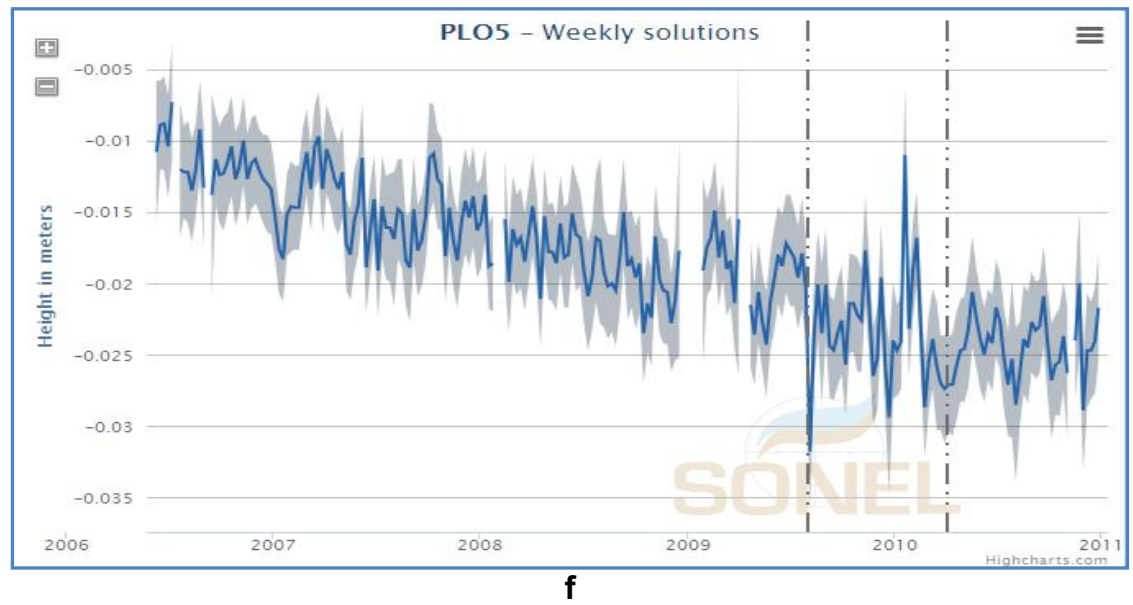

Fig. 2. Continued - measured and fitted sea level patterns in San Diego

a) classic trend computation (from tidesandcurrents.noaa.gov/sltrends/). Relative sea level velocity is $+2.06 \pm 0.23$ $\mathrm{mm} /$ year; b) measured and fitted (equation (3)) monthly average mean sea levels; c) detrended monthly average mean sea levels; d) SLR over the last 20 years.e) present SLR by using different record lengths; f) GPS velocity nearby the tide gauge (from www.sonel.org). Subsidence velocities of nearby domes are $-1.65 \pm 0.41 \mathrm{~mm} /$ year (Point Loma 3, PLO3) and $-3.23 \pm 0.17 \mathrm{~mm} /$ year (Point Loma 5, PLO5) 


\section{DISCUSSION}

The issue raised by [4] does not have any effect on the above conclusions. The oscillations of sea levels are not certainly perfectly sinusoidal and the sea level forcings are certainly many. Clearly, by using different periodic functions that are not exactly sinusoidal and by increasing the number of functions adopted for a fitting like (3), the determination of the periodicities of the oscillations may certainly provide slightly different results. However, this is irrelevant in the optic of the debate on the presence or absence of acceleration in the sea levels.

The linear and sinusoidal models, equation (1) and equation (3) respectively, can be fit by using least squares routines. To obtain a good fit for the sinusoidal (nonlinear) model, least squares routines may require good starting values for the constant, the amplitude, and the periodicity and different approaches may provide slightly different results. This has however not appreciable influence on the results of sea level rise. As with any statistical model, the fit is subjected to graphical and quantitative techniques of model validation up to satisfactory accuracy.

The measured sea level time series suffer of significant inaccuracies difficult or impossible to quantify. This is why the standard practice is to linearly fit the available monthly average mean sea level data mentioning the length and percentage of gaps in the record and the existence of levelling information about a datum. This gives a rate of rise of sea levels and the uncertainty in that value. If the levelling is accurate and the time span of data exceed the 60 years with minimal gaps, then the estimation of the rate of rise is reliable.
In sea levels there are many oscillations, with periodicities from hours to decades very well evidenced in the tide gauge records. The "traditional" analysis of sea levels (see the surveys by PSMSL, NOAA and other major players) is based on the linear fitting of the monthly average mean sea levels. The linear fitting of yearly average mean sea levels is less common but should not return average rates of rise that far. What is important is to linearly fit a time series having length much larger than the periodicity of the longest oscillation detected. Short tide gauge records should not be used to infer any trend.

The uncertainties of the estimation are generally significant and very difficult to be estimated. In the best cases, the tide gauge is periodically levelled versus a datum and every change of the instrument or relocation is carefully monitored to avoid biases. Unfortunately, the absolute tide gauge position is only known since very few years and only in very few locations with accuracy still far from the acceptable. However, at present there is no better measure of sea levels than the tide gauges. When everything has been done properly to avoid biases, there may still be the issue of missing data (gaps).

Clearly, the reliability of a sea level rise estimation reduces the more are the gaps. Somebody as PSMSL and NOAA only use the measured data with gaps. We use either same approach or we do use a fitting with a line and multiple sines to fill the gaps iteratively. As a nonlinear fitting depends on the first guesses of the parameters involved, uncertainties are either way substantial. The total length of the record and the percentage of gaps are two parameters that should be stated close to the rate of rise estimation to give an idea of the reliability of the estimation.

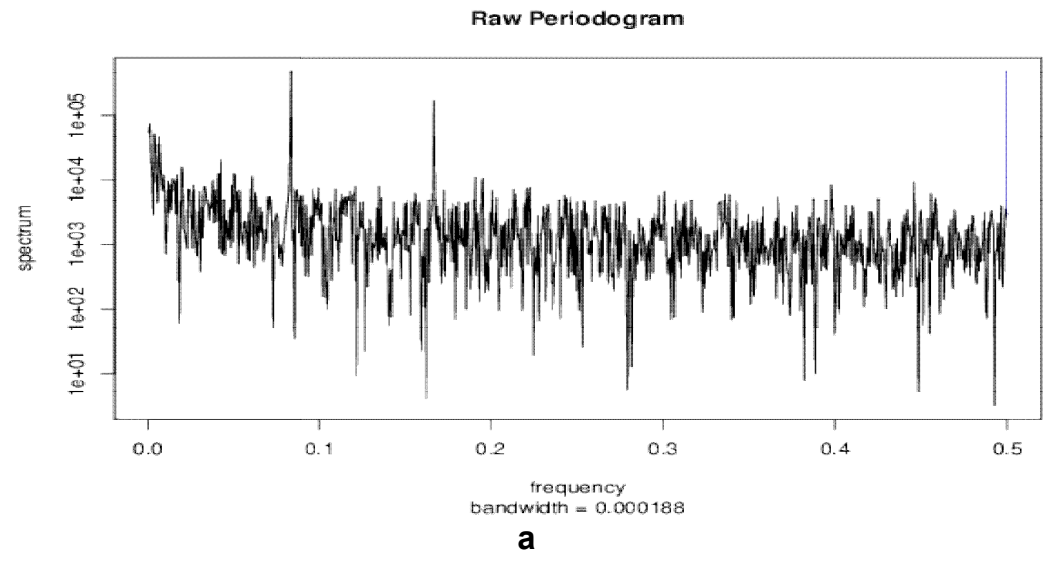



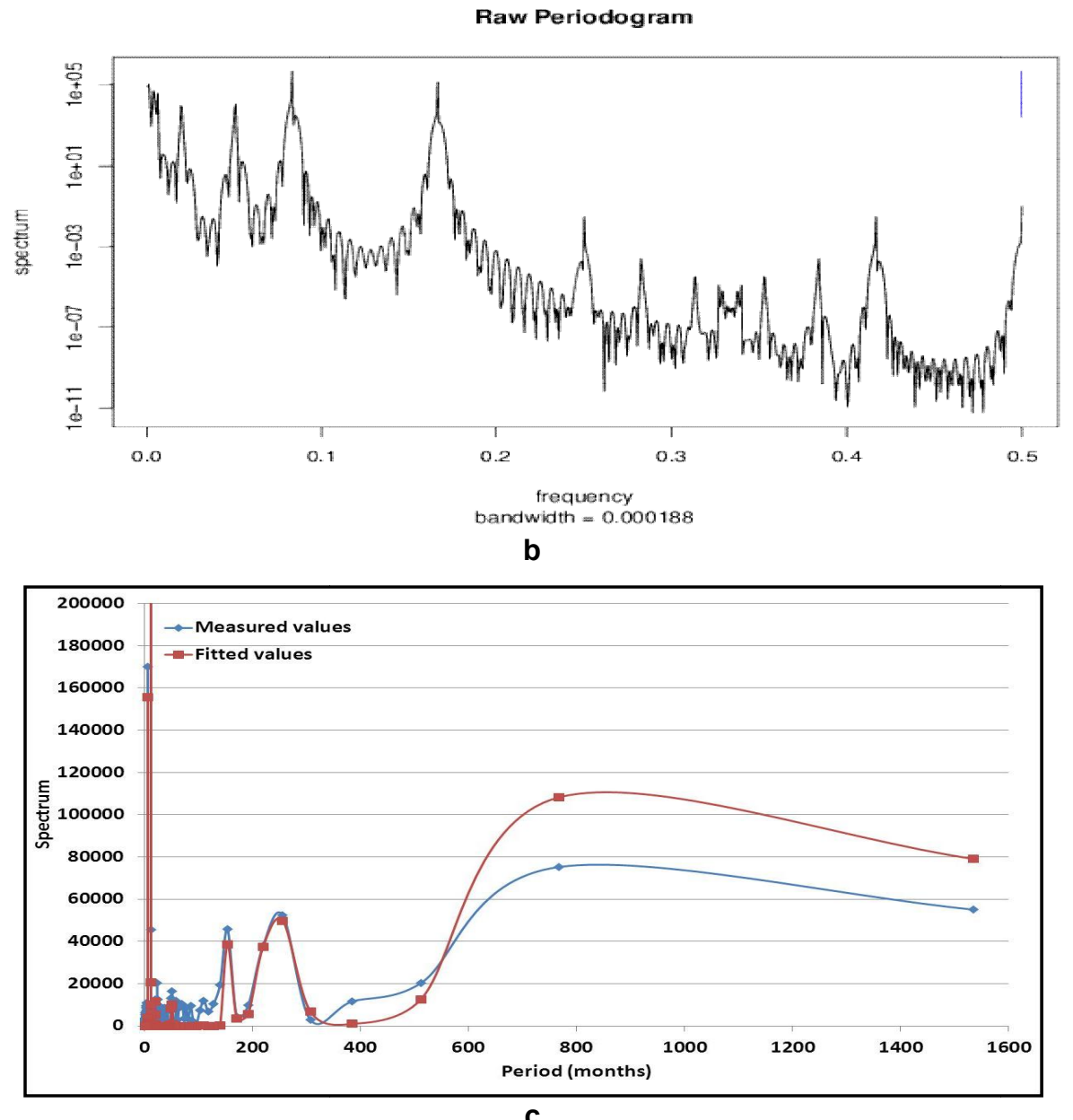

Fig. 3. Periodogram of the measured and fitted sea level patterns in Sydney a) periodogram spectrum vs. frequency (in month $s^{-1}$ ) of the measured monthly average mean sea levels; $b$ ) periodogram spectrum vs. frequency (in month ${ }^{-1}$ ) of the monthly average mean sea levels from the fitting with a line and sines; c) periodogram spectrum vs. period (in months) of the measured and fitted monthly averages. Images a) and b) and data of c) are obtained by [13]

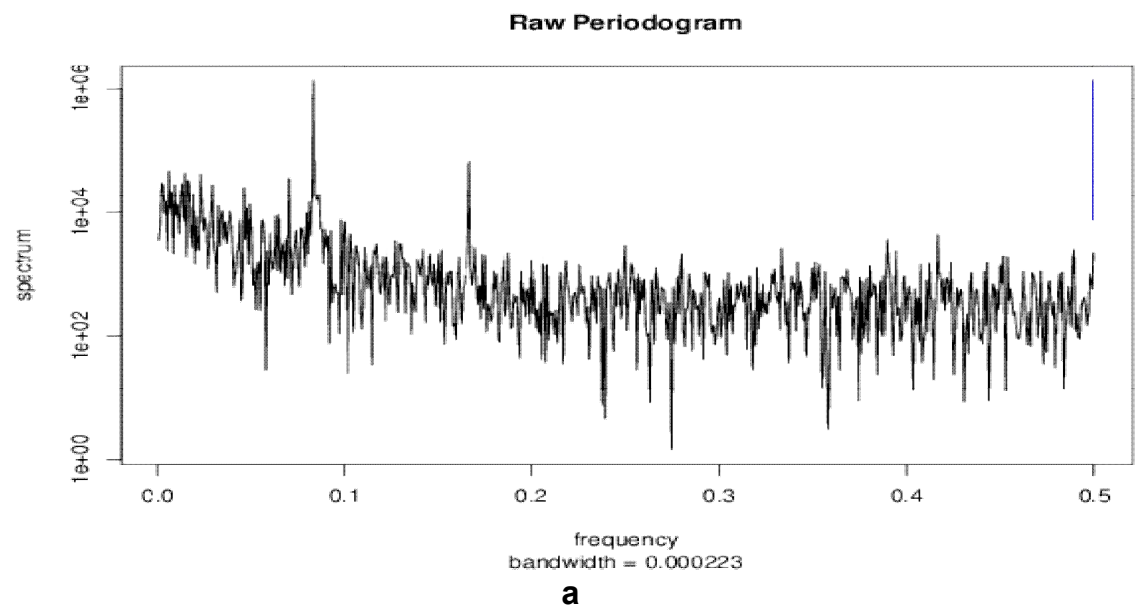



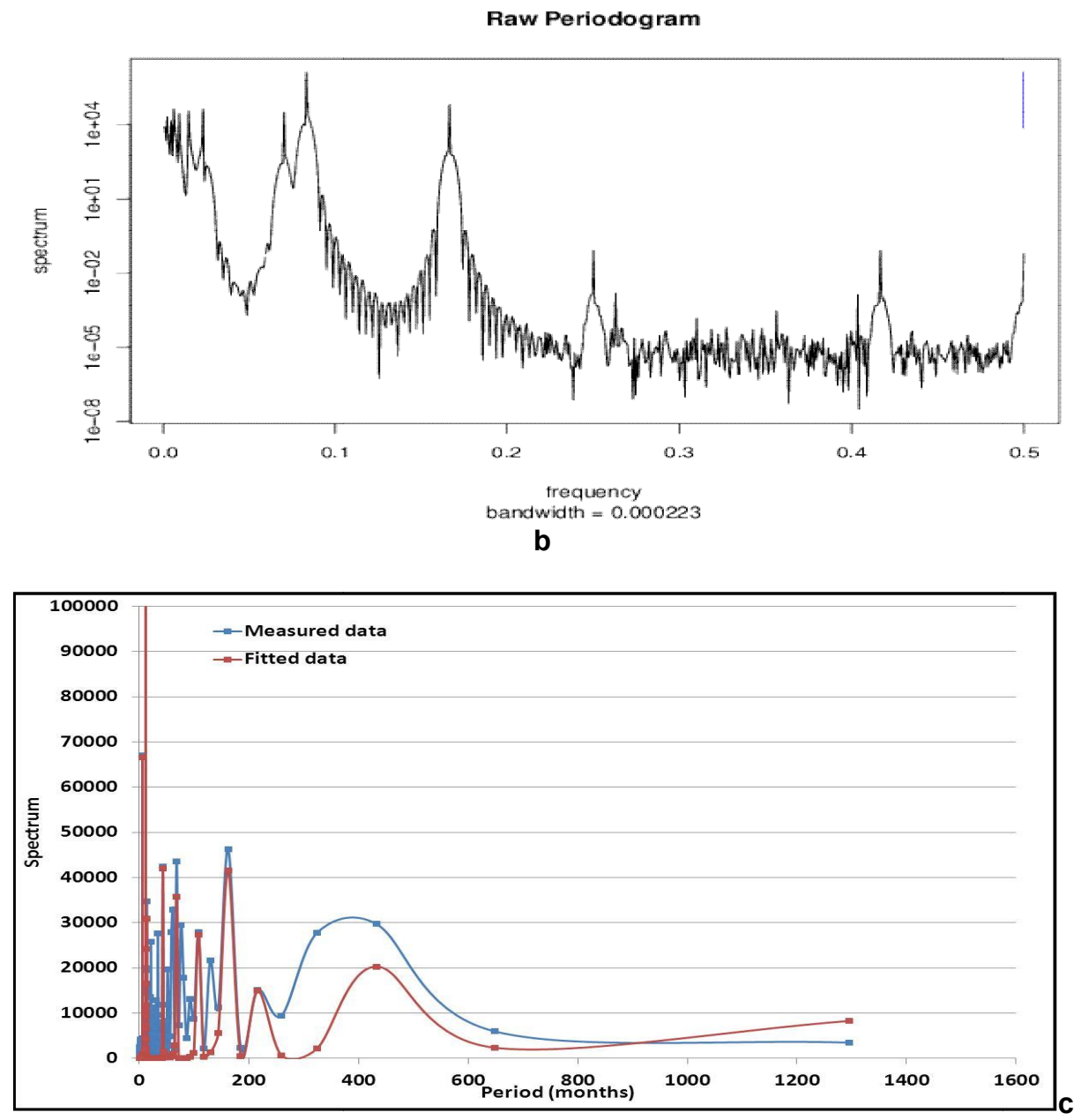

Fig. 4. Periodogram of the measured and fitted sea level patterns in San Diego

a) periodogram spectrum vs. frequency (in month ${ }^{-1}$ ) of the measured monthly average mean sea levels; b) periodogram spectrum vs. frequency (in month ${ }^{-1}$ ) of the monthly average mean sea levels from the fitting with a line and sines; c) periodogram spectrum vs. period (in months) of the measured and fitted monthly averages. Images a) and b) and data of c) are obtained by [13].

\section{CONCLUSION}

In view of the only $+0.25 \mathrm{~mm} / \mathrm{year}$ of the present relative rate of rise at the acceleration free worldwide average tide gauge by classic, simple methods, with an overwhelming contribution by subsidence, there is no reason to question how accurate may be the estimation of the multidecadal periodicities to void the assessment of the velocity and acceleration of sea levels very far from the climate model predictions.

If the sea levels have to rise of 1 meter by 2100 and not of only 21.5 millimeters at the worldwide average tide gauge, there is a problem of orders of magnitude difference in the sea levels computed (by climate models) and measured (by tide gauges).
The best data we do have for sea levels is the one included in the Permanent Service on Mean Seal Level data base that is everything but perfect. The analysis of these data are however much better than any philosophical assumption even if popular these days (a theory not validated by experiments is philosophy and not science).

\section{COMPETING INTERESTS}

Authors have declared that no competing interests exist.

\section{REFERENCES}

1. Carter $R M$, de Lange $W$, Hansen $J M$, Humlum $O$, Idso C, Kear D, Legates D, Mörner N A, Ollier C, Singer F, Soon W 
Commentary and Analysis on the Whitehead \& Associates. NSW Sea-Level Report, NIPCC Report Reference. 2014;E13.7268.

Available:http://heartland.org/sites/default/fi les/nipcc report on nsw coastal sl -

$9 \mathrm{z}$ corrected.pdf

2. Parker A. minimum 60 years of recording are needed to compute the sea level rate of rise in the western south pacific, Nonlinear Engineering. 2014;3(1)1-10.

DOI 10.1515/nleng-2013-0011.

3. Permanent Service on Mean Seal Level; 2014.

Available:www.psmsl.org/products/trends/t rends.txt.

4. Foster G, Brown PT. Time and Tide: Analysis of Sea Level Time Series. Climate Dynamics, in press; 2014.

DOI:10.1007/s00382-014-2224-3

5. Holgate S. On the decadal rates of sea level change during the twentieth century, Geophysical Research Letters. 2007;34: L01602.

6. Chambers DP, Merrifield MA, Nerem RS. Is there a 60-year oscillation in global mean sea level?, Geophysical Research Letters. 2012;39(18):L18607.

7. Marcos M, Tsimplis MN, Calafat FM. Interannual and decadal sea level variations in the north-western Pacific marginal seas. Progress In Oceanography. 2013;105:421.
8. Parker A, Saad Saleem M, Lawson M. Sea-Level Trend Analysis for Coastal Management, Ocean \& Coastal Management. 2013;73:63-81.

9. Soon W, Legates DR. Solar irradiance modulation of Equator-to-Pole (Arctic) temperature gradients: empirical evidence for climate variation on multi-decadal timescales, Journal of Atmospheric, Solar \& Terrestrial Physics. 2013;93:45-56.

10. Pugh D. Changing sea levels: Effects of tides, weather and climate. Cambridge University Press, Cambridge, UK. 2004; 265.

11. Yndestad H, Turrell WR, Ozhigin V. Lunar nodal tide effects on variability of sea level, temperature, and salinity in the FaroeShetland Channel and the Barents Sea, Deep Sea Research. 2004;1(55):12011217.

12. Mörner N. Solar Wind, Earth's Rotation and Changes in Terrestrial Climate. Physical Review \& Research International. 2013;3(2):117-136.

13. Wessa P. Spectral Analysis (v1.0.8) in Free Statistics Software (v1.1.23-r7), Office for Research Development and Education; 2012.

Available:http://www.wessa.net/rwasp spe ctrum.wasp/

(c) 2015 Parker and Ollier; This is an Open Access article distributed under the terms of the Creative Commons Attribution License (http://creativecommons.org/licenses/by/4.0), which permits unrestricted use, distribution, and reproduction in any medium, provided the original work is properly cited.

Peer-review history:

The peer review history for this paper can be accessed here: http://www.sciencedomain.org/review-history.php?iid=837\&id=33\&aid=8091 